\title{
Non-Coding RNAs in Cardiac Aging
}

\author{
Hui Wanga Yihua Beib,c Jing Shia Junjie Xiao ${ }^{b, c} \quad$ Xiangqing Kong ${ }^{a}$
}

${ }^{a}$ Department of Cardiology, The First Affiliated Hospital of Nanjing Medical University, Nanjing,

${ }^{b}$ Regeneration and Ageing Lab, Experimental Center of Life Sciences, School of Life Science, Shanghai University, Shanghai, 'Shanghai Key Laboratory of Bio-Energy Crops, School of Life Sciences, Shanghai

University, Shanghai, China

\section{Key Words}

Aging • Heart • Non-coding RNAs • MicroRNAs • IncRNAs

\begin{abstract}
Aging has a remarkable impact on the function of the heart, and is independently associated with increased risk for cardiovascular diseases. Cardiac aging is an intrinsic physiological process that results in impaired cardiac function, along with lots of cellular and molecular changes. Non-coding RNAs include small transcripts, such as microRNAs and a wide range of long non-coding RNAs (IncRNAs). Emerging evidence has revealed that non-coding RNAs acted as powerful and dynamic modifiers of cardiac aging. This review aims to provide a general overview of non-coding RNAs implicated in cardiac aging, and the underlying mechanisms involved in maintaining homeo-stasis and retarding aging.
\end{abstract}

\section{Introduction}

Cardiovascular diseases are among leading causes of death worldwide [1]. Countries around the world are experiencing a dramatic increase in the elderly population (aged over 65) [1].The increased trend of aging and age-associated risk factors such as hypertension, diabetes, hypercholesterolemia, smoking and other risk factors contribute to increased cardiovascular mortality and morbidity in the elderly [1]. Moreover, the heart undergoes slowly progressive structural changes in aging, that lead to decreased functionality [2]. Better understanding of cardiac aging might help improve currently available therapies and

H. Wang and Y. Bei contributed equally to this work.

Prof. Xiangqing Kong

and Dr. Junjie Xiao

\section{KARGER 125}

Department of Cardiology, The First Affiliated Hospital of Nanjing Medical University, 300 Guangzhou Road, Nanjing 210029, (China); and Regeneration and Ageing Lab and Experimental Center of Life Sciences, School of Life Science, Shanghai University, 333 Nan Chen Road, Shanghai 200444 (China)

E-Mail xiangqingkong_nj@163.com, E-Mail junjiexiao@shu.edu.cn 
reduce risk factors of cardiovascular diseases [2]. Therefore, elucidation of the molecular mechanisms contributing to cardiac aging in healthy heart would help to identify early pathophysiological changes in the heart [2].

Cardiac senescence is a multifactorial process, and the discovery of non-coding RNAs has provided new molecular insights into cardiac aging. In this review, we describe the emerging impact of non-coding RNAs on cellular senescence and their possible implications in cardiac aging.

\section{Cellular senescence of cardiac aging}

The hallmarks of cardiac aging mainly include: left ventricular hypertrophy, diastolic dysfunction, diminished left ventricular systolic reverse capacity, valvular degeneration and increased cardiac fibrosis [2] (Fig.1). Aging-associated alteration of cardiac function affects the cellular composition of the heart as well. The key component of the aging process is cellular senescence. According to the dependence on telomerase, it can be separated into two categories: replicative senescence or stress-induced premature senescence (SIPS). Replicative senescence is naturally lost the ability to regenerate along with the age among which telomere shortening induce a DNA damage response (DDR). In contrast, SIPS is an alternative telomere-independent prematurely process triggered by external stimuli, including oxidizing agents and radiation. SIPS shares many morphological and molecular characteristics to replicative senescence except telomere shortening $[3,4]$. Senescent cells display a characteristic senescence-associated phenotype, including a large flattened morphology, growth-arrest, telomere shorting, senescence-associated secretory phenotype (SASP), DDR proteins and lysosomal beta-galactosidase (SA- $\beta$-Gal) activity. Tumor suppressor networks such as $\mathrm{p} 53 / \mathrm{p} 21$ and p16/RB pathways triggering senescence are used as markers as well $[5,6]$. Moreover, apoptosis and necrosis, coupled with fibrosis also play pivotal roles in cell aging [2].

The heart is mainly composed of two entirely different types of cells: cardiac myocytes and non-myocytes (mainly fibroblasts). Cardiomyocytes display a number of physiological and morphological features affected by aging. As we all known, cardiomyocytes attain their final differentiated state early during the lifespan and the capacity of cardiomyocyte renewal is limited. The total number of cardiomyocytes in the heart decreases with aging due to senescence, necrosis ,apoptosis and cardiac stem cell reserves loss [7, 8].The alterations in myocyte activation, contraction and relaxation, hypertrophy, and an inability to repair or replace lost cells contribute to the decline of cardiac function [9]. The aging heart is associated with morphological and structural remodeling that lead to functional recession. Cardiac fibroblasts are the most abount cell types in the heart, accounting for approximately $70 \%$ of the total cell number in the heart. Cardiac fibroblasts are also required for cardiac remodeling [10,11].Cardiac fibroblasts undergo senescence, growth-arrest and epithelialmesenchymal transition (EMT) $[12,13]$. Cellular senescence is the universal and fundamental process of aging. Thus, understanding the molecular mechanisms that govern the senescent phenotype greatly facilitate therapeutic treatment of cardiac aging.

\section{Non-coding RNAs}

Non-coding RNAs comprise a huge heterogeneous family that includes many different subtypes, including transfer RNAs (tRNAs), ribosomal RNAs (rRNAs), piwi-interacting RNAs (piRNAs), small nucleolar RNAs (snoRNAs), small nuclear RNAs (snRNAs) and enhancerlike RNAs (eRNAs) [14]. The ncRNAs are arbitrarily divided into short $(<200 \mathrm{nt}$, mainly microRNAs), and long (>200 nt) ncRNAs accordingly to their size [15]. Small ncRNAs such as microRNAs (miRNAs, miRs) regulate the expression of target genes at the level of translation or mRNA stability [6]. Besides well-explored miRNAs, lncRNAs have recently emerged as 


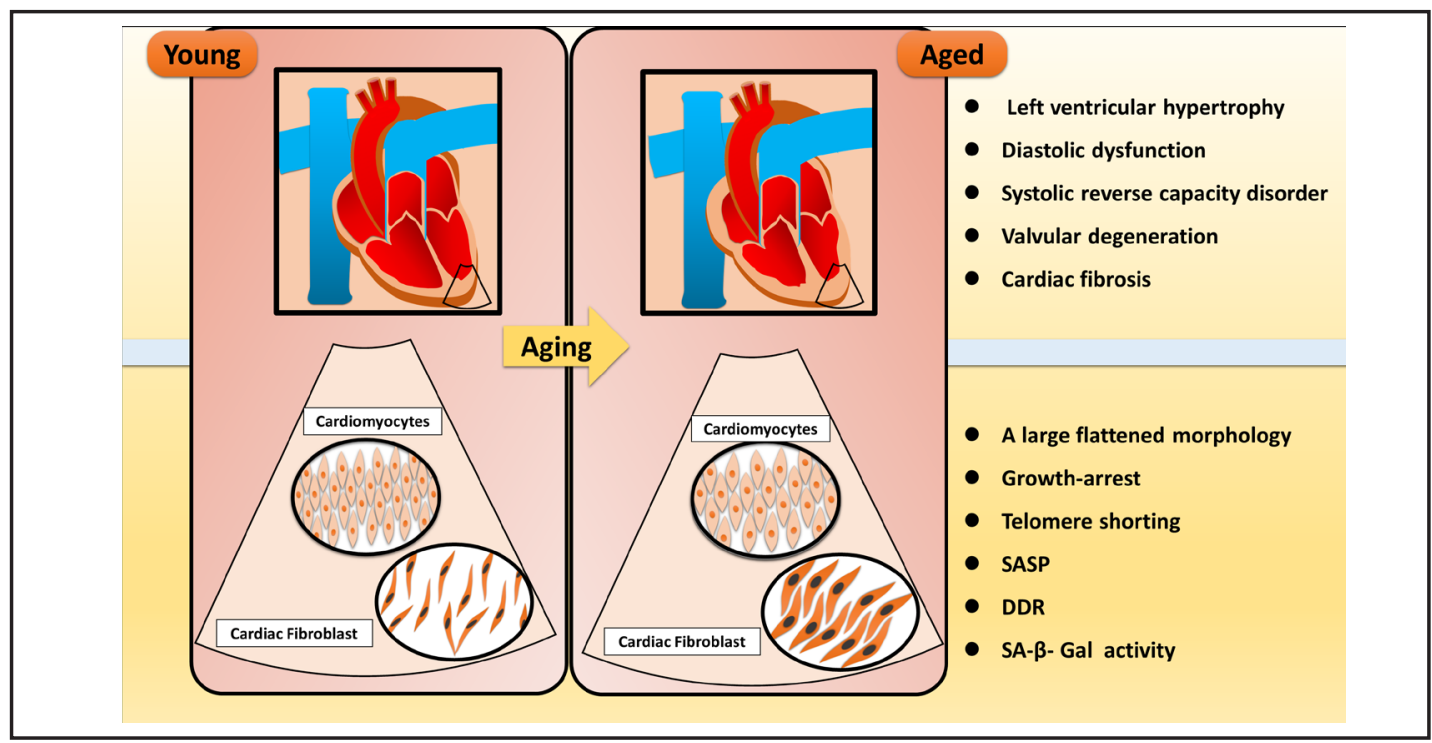

Fig. 1. Age-dependent changes to cardiac tissues. The impact of aging on the heart and cell is summarized. Both the heart and cell undergo numerous alterations during cardiac aging, leading to the degeneration of cardiac function.

Table 1. Roles of non-coding RNAs in cellular senescence

\begin{tabular}{llllc}
\hline microRNAs & Cell Type & Target & Function & Ref \\
\hline miR-34a & Cardiomyocytes & PNUTS & Pro-aging & 30 \\
miR-18/19 & Cardiomyocytes & CTGF/TSP-1 & Anti-aging & 12 \\
miR-17-3p & Cardiac fibroblast & Par4 & Anti-aging & 13 \\
miR-22 & Cardiac fibroblast & mimecan & Pro-aging & 44 \\
IncRNAs & & & & \\
SAL-RNA1 & Human diploid fibroblasts & & Anti-aging & 53 \\
SAL-RNA2 & Human diploid fibroblasts & & Anti-aging & 53 \\
SAL-RNA3 & Human diploid fibroblasts & & Anti-aging & 53 \\
MALAT1 & Human diploid fibroblasts & & Anti-aging & 53 \\
MIAT & WI-38 & & Anti-aging & 53 \\
& WI-38 & & & \\
\hline
\end{tabular}

important molecules in several cellular processes. Here, we will review miRNAs and IncRNAs for their regulatory roles in cellular senescence (Table 1), with special attention to their contribution to cardiac aging.

\section{MiRNAs}

MiRNAs are the most explored small ncRNAs that function as critical regulators of gene expression. The production of miRNAs is a multistep process. Most of miRNAs are transcribed by RNA polymerase II/III to primary-miRNA (pri-miR) $[16,17]$. The pri-miRNA is further processed by Drosha into a 60- to 70-nucleotide precursor named pre-miRNA in the nucleus and subsequently transferred to cytoplasm via exportin-5/RanGTP [18-20]. In the cytoplasm, the pre-miRs are further modified by the nuclease Dicer, to produce a miRNA duplex [21,22]. The mature miRNA combined with Argonaut (Ago) proteins are loaded into the RNA-induced silencing complex (RISC) to repress target gene expression [23]. Mature 
miRNAs through pairing to the $3^{\prime}$-untranslated ( $3^{\prime} \mathrm{UTR}$ ) region to inhibit target genes mRNA translation or promote mRNA degradation [24]. As a class of regulatory molecules, miRNAs participate in many physiological and pathological processes including heart development [25], regeneration [26], hypertrophy [27], contractility [28] and fibrosis [29]. MiRNAs have recently emerged as important regulators of cellular senescence and aging. Therefore, we outline the miRNAs function in cardiac degeneration as following.

\section{MiR-34a/PNUTS}

Recently, Boom et al. identified the involvement of miR-34a/PNUTS in aging-induced cardiac degeneration and suggested the potential of miR-34a as a therapeutic target in the setting of cardiac aging [30]. They evaluated differentially expressed miRNAs profiling between young (6-8 weeks old) and aged (18-20months old) mice and identified that the entire miR-34 family was significantly up-regulated in the hearts of aged mice. Quantitative real-time polymerase chain reaction (PCR) and in situ hybridization further confirmed that miR-34a positively correlated with age and miR-34a was predominantly expressed in cardiomyocytes. MiR-34a knockout mice prevented ventricular remodeling in aging-induced cardiac senescence. Inhibition of miR-34a by locked nucleic acid (LNA)-based antimiRs also abolished deterioration of cardiac contractile function in Ku80-/-mice, a genetic mouse model of accelerated aging [30]. In the process of cellular aging, DNA damage and p53 activation lead to cell-cycle arrest at the G2-M DNA damage checkpoint. MiR-34a is a ubiquitously expressed miRNA, which is transcriptionally regulated by a tumor suppressor gene P53. The link of DNA damage, p53, and miR-34a signaling was also found in cancer [31]. Moreover, in endothelial cells and endothelial progenitor cells, miR-34a enhances cellular senescence and reduces longevity through its direct target SIRT1 [32, 33]. Interestingly, miR-34a was increased in human hearts with age, suggesting that miR-34a plays a similar role in human cardiac aging [30]. Protein phosphates 1 nuclear targeting subunit (PNUTS) is a nuclearlocalized protein that functions as a new component of the DNA damage [34] and it can also interact with telomere regulator TRF2 [35]. PNUTS was downregulated at the protein level in aged hearts and increased in genetic deletion of miR-34a mice. Using bioinformatics analyses and validated using luciferase reporter assays, PNUTS was identified as a direct target of miR-34a. Therefore, miR-34a/PNUTS pathway induces telomere shortening, DNA damage repair and provokes cardiac senescence, contributing to cardiac aging. Transient therapeutic suppression of miR-34a or increasing PNUTS activity may ameliorate cardiac aging. Besides in aged cardiac myocytes, miR-34a/PNUTS axis is also activated in cardiomypcyte progenitor cells that destroying its intrinsic regenerative capacity [36]. The finding of miR-34a/PNUTS mediated cellular senescence provides new insights in the complex cardiac aging puzzle.

\section{MiR-18/19-CTGF/TSP-1}

Age-related cardiac remodeling is known to be accompanied by extracellular matrix (ECM) synthesis and deposition. ECM proteins include fibronectin [37], thrombospondin-2 (TSP-2) [38], and connective tissue growth factor (CTGF) [39] increase with aging. The miR17-92 cluster, consisting of six mature miRNAs (miR-17, miR-18a, miR-19a, miR-20a, miR19-b1, and miR-92a-1) has been reported to play fundamental role in heart development and remodeling [40]. CTGF and TSP-1 have been identified as target genes of miR-18a and miR19 [41]. In agreement with these findings, miR-18a and miR-19a were strongly repressed in aged cardiomyocytes with concomitant increased expression of CTGF and TSP-1. MiR-18/19 and CTGF/TSP-1 have been causally linked to aging-related fibrotic remodeling of the heart upon HF [12]. Modulation cardiomyocyte-derived miR-18/19 affected cardiac ECM protein CTGF and TSP- 1 and collagens type 1 and 3 in cardiac aging. 


\section{MiR-17-3p/Par4}

The presence of growth-arrest, shorter telomeres and makers including lysosomal senescence-associated beta-galactosidase (SA- $\beta$ - Gal) activity and DDR proteins can be used to assess cells aging. Lower intensities of $\beta$-gal staining were detected in miR-17-3p transgenic mice heart, indicating the involvement of miR-17-3p in cardiac senescence. Expression of miR-17-3p extended survival and retarded senescence in mouse cardiac fibroblast (MCF) cell line. In addition, the expression of miR-17-3p in aging hearts was lower than the young hearts. Par-4 was demonstrated to be a direct target of miR-17 [13]. Par4 , known as pro-apoptotic protein, is a critical regulator of tumor cell survival and is also required for cell apoptosis [42, 43]. Par4 negatively regulates its transcript factors, CEBPB and Focal Adhesion Kinase (FAK), which promotes MCF epithelial-mesenchymal transition (EMT) and self-renewal, resulting in cellular senescence and apoptosis-resistance. MiR-173 p plays an anti-aging role by targeting Par4, and promoting CEBPB/FAK senescence related signaling pathway in the transgenic mice and transfected cells [13].

\section{MiR-22/mimecan}

To identify aging-associated changes in miRNA expression profiles in the murine heart, miRNA expression profiles in hearts of neonatal, 4 weeks old, 6 months and 19 months old mice were analyzed. Notably, miR-22 was demonstrated to have an aging-associated increase trend. Moreover, the expression of miR-22 was higher in cardiac fibroblasts and smooth muscle cells compared to cardiomyocytes and endothelial cells. Inverse correlation with miR-22, mimecan expression gradually decreased during cardiac aging indicating that mimecan may be a target for miR-22 in the heart. Direct mimecan regulation by miR22 was also confirmed by using a luciferase reporter gene approach. Localisation studies demonstrated that mimecan co-localized with cardiac fibroblasts and smooth muscle cells, while no co-localization between mimecan and endothelial cells or cardiomyocytes was observed. Senescence associated SA- $\beta$-Gal activity in neonatal cardiac fibroblasts was detected to determine the function of miR-22 in cellular senescence of cardiac fibroblasts. Overexpressing miR-22 or silencing mimecan resulted in a significant increase of senescent cells in cardiac fibroblasts, suggesting a pro-aging function of miR-22 [44].

\section{LncRNAs}

LncRNAs vary widely in size, biogenesis and function. According to different transcriptional site, IncRNAs can be divided into the following categories: lincRNAs, transcribed from intergenic regions; antisense lncRNAs, from the opposite strand of mRNAs; pseudogeneencoded lncRNAs from vestigial genes that lost their coding potential; long intronic ncRNAs, from introns of annotated genes; promoter-associated lncRNAs, from the promoter regions of coding mRNAs and circular RNAs, generated by the splicing machinery [45]. Among the range of RNA molecules, IncRNAs function as an additional regulator of the genome controlling via multiple mechanisms. As transcriptional regulators, lncRNAs modulate transcription initiation by RNA polymerase II [46, 47]. In addition, IncRNAs can also mediate gene expression post-transcriptionally by base-pairing with mRNAs to modulate their translation or stability $[48,49]$ and by interfering with RNA-binding proteins to influence splicing and translation [50]. LncRNAs accumulate in large numbers and modulate gene expression in different ways, including acting as cofactors, competitors or decoys of RBPs or miRNAs [51]. The discovery of lncRNAs highlights the rising interest in the roles of lncRNAs as a potentially new and crucial layer of biological regulation. 


\section{Senescence-associated IncRNAs}

LncRNAs play important roles in the onset and progression of various diseases, including aging-related diseases such as cancer [52], cardiovascular pathologies [53, 54], and neurodegenerative disorders [55]. Growing evidences suggest that lncRNAs influence the molecular processes underlying aging-associated phenotypes. Here, we give some examples to illustrate the mechanisms underlying lncRNAs in cellular senescence.

The limited division potential of normal human diploid fibroblast cells in vitro is well documented and has been established as a model for cellular aging. The RNA sequencing between senescent and proliferating young human diploid fibroblasts identified that the expression of lncRNAs changed significantly after aging. The alterations of lncRNAs such as antisense lncRNAs and pseudogene-encoded lncRNAs link the association with senescence. Among those senescence-associated lncRNAs (SAL-RNAs), silencing SAL-RNA2 (XLOC_025931) or SAL-RNA3 (XLOC_025918) increased expression of p53 and cleaved PARP, a marker of apoptosis. These results suggested the protective role of SAL-RNA2 and SALRNA3 (XLOC_025931 and XLOC_025918) in the survival of senescent fibroblasts. However, silencing SAL-RNA1 (XLOC_023166) in early-passage fibroblasts enhanced the senescent phenotype including an enlarged morphology, positive $\beta$-galactosidase activity, and heightened senescence protein markers p21 and p53. SAL-RNA1 may serve as a preventive factor in the early onset of senescence. Furthermore, the function of MALAT1 and MIAT in senescence cell was also tested in WI-38 fibroblasts. Knockdown of MALAT1 and MIAT using small interfering (si)RNAs accelerated aging [56]. Another group also found that MALAT1-depleted cells showed enhanced $\beta$-galactosidase ( $\beta$-gal) staining, indicating cellular senescence of human fibroblasts. MALAT1 regulates cell cycle by modulating the gene expression of transcription factors in G1-to-S transition. Deleting of MALAT1 leads to cell proliferation blocks and undergoes aging [57].

Despite rising interest in the expression and function of lncRNAs, their possible roles in cardiac cell senescence remain incompletely characterized at present. Further experimental studies are needed to better understanding of the biological function of lncRNAs in cardiac aging.

\section{Conclusion}

The rapidity of the population's aging has made it more urgent for the adoption of countermeasures. In this review, we summarized the current knowledge about the function of non-coding RNAs in cardiac aging. As multi-tasking molecules in the cell, non-coding RNAs have a variety of effects on aging associate cellular senescence. The use of transgenic mice that intervene certain miRNAs (for example, miR-34a) could be beneficial to cardiac degeneration, indicating that miRNAs can be used as a powerful therapeutic tool to anti-aging by fine-tuning target proteins. Although little is known about lncRNAs in cardiac aging, given the variety of functions and biological mechanisms regulated by lncRNAs and considering the rapid progress in our knowledge of lncRNAs, it is likely that lncRNAs will affect cardiac aging broadly. A more comprehensive understanding of specific miRNAs or lncRNAs regulating gene expression in cellular senescence can help develop new and more effective non-coding RNAs-based interventions to ameliorate the losses of advancing age. In addition, it is highly desirble to develop novel strategy for time-phase and cell-type specific delivery of miRNA antagomirs or mimics. Non-coding RNAs have become promising molecular tools and targets in our efforts to restore age-dependent losses in body homeostasis.

\section{Disclosure Statement}

The authors declare there are no conflicts of interest.

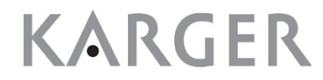




\section{Cellular Physiology Cell Physiol Biochem 2015;36:1679-1687 \begin{tabular}{l|l} 
and Biochemistry Publisned onIIne: July 13, 2015 & $\begin{array}{l}\text { C) 2015 S. Karger AG, Basel } \\
\text { www.karger.com/cpb }\end{array}$ \\
\hline
\end{tabular}}

Wang et al.: Non-Coding RNAs Contributes to Cardiac Aging

\section{Acknowledgments}

This work was supported by the grants from National Natural Science Foundation of China (81200169 to JJ Xiao), Innovation Program of Shanghai Municipal Education Commission (13YZ014 to JJ Xiao), Foundation for University Young Teachers by Shanghai Municipal Education Commission (year 2012, to JJ Xiao), Innovation fund from Shanghai University (sdcx2012038 to JJ Xiao), and Program for the integration of production, teaching and research for University Teachers supported by Shanghai Municipal Education Commission (year 2014, to JJ Xiao). Dr XQ Kong is a Fellow at the Collaborative Innovation Center For Cardiovascular Disease Translational Medicine.

\section{Reference}

1 North BJ, Sinclair DA: The intersection between aging and cardiovascular disease. Cir Res 2012;110:10971108.

2 Dai DF, Chen T, Johnson SC, Szeto H, Rabinovitch PS: Cardiac aging: From molecular mechanisms to significance in human health and disease. Antioxid Redox Signal 2012;16:1492-1526.

- 3 Sikora E, Arendt T, Bennett M, Narita M: Impact of cellular senescence signature on ageing research. Ageing Res Rev 2011;10:146-152.

4 Wang JC, Bennett M: Aging and atherosclerosis: Mechanisms, functional consequences, and potential therapeutics for cellular senescence. Cir Res 2012; 111: 245-259.

5 Debacq-Chainiaux F, Erusalimsky JD, Campisi J, Toussaint 0: Protocols to detect senescence-associated beta-galactosidase (sa-betagal) activity, a biomarker of senescent cells in culture and in vivo. Nat Protoc 2009;4:1798-1806.

6 Gorospe M, Abdelmohsen K: Microregulators come of age in senescence. Trends Genet 2011;27:233-241. Goldspink DF, Burniston JG, Tan LB: Cardiomyocyte death and the ageing and failing heart. Exp Physiol 2003;88:447-458.

8 Olivetti G, Melissari M, Capasso JM, Anversa P: Cardiomyopathy of the aging human heart. Myocyte loss and reactive cellular hypertrophy. Cir Res 1991;68: 1560- 1568.

9 Sheydina A, Riordon DR, Boheler KR: Molecular mechanisms of cardiomyocyte aging. Clin Sci (Lond) 2011;121:315-329.

10 Takeda N, Manabe I, Uchino Y, Eguchi K, Matsumoto S, Nishimura S, Shindo T, Sano M, Otsu K, Snider P, Conway SJ, Nagai R: Cardiac fibroblasts are essential for the adaptive response of the murine heart to pressure overload. J Clin Invest 2010; 120:254-265.

11 Porter KE, Turner NA: Cardiac fibroblasts: At the heart of myocardial remodeling. Pharmacol Ther 2009;123:255-278.

12 van Almen GC, Verhesen W, van Leeuwen RE, van de Vrie M, Eurlings C, Schellings MW, Swinnen M, Cleutjens JP, van Zandvoort MA, Heymans S, Schroen B: Microrna-18 and microrna-19 regulate ctgf and tsp-1 expression in age-related heart failure. Aging Cell 2011;10:769-779.

13 Du WW, Li X, Li T, Li H, Khorshidi A, Liu F, Yang BB: The microrna mir-17-3p inhibits mouse cardiac fibroblast senescence by targeting par4. J Cell Sci 2015; 128: 293-304.

14 Derrien T, Johnson R, Bussotti G, Tanzer A, Djebali S, Tilgner H, Guernec G, Martin D, Merkel A, Knowles DG, Lagarde J, Veeravalli L, Ruan X, Ruan Y, Lassmann T, Carninci P, Brown JB, Lipovich L, Gonzalez JM, Thomas M, Davis CA, Shiekhattar R, Gingeras TR, Hubbard TJ, Notredame C, Harrow J, Guigo R: The gencode v7 catalog of human long noncoding rnas: Analysis of their gene structure, evolution, and expression. Genome Res 2012;22:1775-1789.

15 Yoon JH, Abdelmohsen K, Gorospe M: Functional interactions among micrornas and long noncoding rnas. Semin Cell Dev Biol 2014;34:9-14.

-16 Lee Y, Kim M, Han J, Yeom KH, Lee S, Baek SH, Kim VN: Microrna genes are transcribed by rna polymerase II. EMBO J 2004;23:4051-4060.

17 Borchert GM, Lanier W, Davidson BL: Rna polymerase III transcribes human micrornas. Nat Struct Mol Biol 2006;13:1097-1101. 


\section{Cellular Physiology Cell Physiol Biochem 2015;36:1679-1687

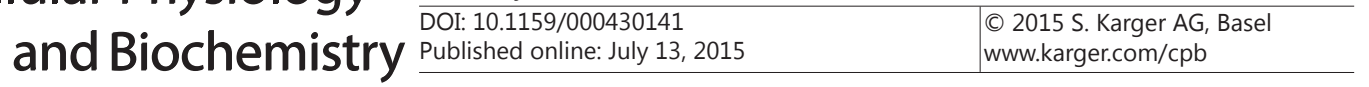

Wang et al.: Non-Coding RNAs Contributes to Cardiac Aging

18 Lee Y, Jeon K, Lee JT, Kim S, Kim VN: Microrna maturation: Stepwise processing and subcellular localization. EMBO J 2002;21:4663-4670.

19 Han J, Lee Y, Yeom KH, Kim YK, Jin H, Kim VN: The drosha-dgcr8 complex in primary microrna processing. Genes Dev 2004;18:3016-3027.

20 Bohnsack MT, Czaplinski K, Gorlich D: Exportin 5 is a rangtp-dependent dsrna-binding protein that mediates nuclear export of pre-mirnas. RNA 2004; 10:185-191.

-21 Bernstein E, Caudy AA, Hammond SM, Hannon GJ: Role for a bidentate ribonuclease in the initiation step of rna interference. Nature. 2001;409:363-366.

-22 Lau NC, Lim LP, Weinstein EG, Bartel DP: An abundant class of tiny rnas with probable regulatory roles in caenorhabditis elegans. Science. 2001;294:858-862.

23 Schwarz DS, Hutvagner G, Du T, Xu Z, Aronin N, Zamore PD: Asymmetry in the assembly of the rnai enzyme complex. Cell 2003;115:199-208.

-24 Shin C, Nam JW, Farh KK, Chiang HR, Shkumatava A, Bartel DP: Expanding the microrna targeting code: Functional sites with centered pairing. Mol Cell 2010; 38:789-802.

25 Li M, Hu X, Zhu J, Zhu C, Zhu S, Liu X, Xu J, Han S, Yu Z: Overexpression of mir-19b impairs cardiac development in zebrafish by targeting ctnnb1. Cell Physiol Biochem 2014;33:1988-2002

26 Wang L, Cui Y, Tang M, Hu X, Luo H, Hescheler J, Xi J: Puerarin facilitates t-tubule development of murine embryonic stem cell-derived cardiomyocytes. Cell Physiol Biochem 2014;34:383-392

27 Tu Y, Wan L, Bu L, Zhao D, Dong D, Huang T, Cheng Z, Shen B: Microrna-22 downregulation by atorvastatin in a mouse model of cardiac hypertrophy: A new mechanism for antihypertrophic intervention. Cell Physiol Biochem 2013;31:997-1008

28 Ning B, Qi X, Li Y, Liu H, Zhang F, Qin C: Biventricular pacing cardiac contractility modulation improves cardiac contractile function via upregulating serca 2 and mir-133 in a rabbit model of congestive heart failure. Cell Physiol Biochem 2014;33:1389-1399

-29 van Rooij E, Sutherland LB, Liu N, Williams AH, McAnally J, Gerard RD, Richardson JA, Olson EN: A signature pattern of stress-responsive micrornas that can evoke cardiac hypertrophy and heart failure.P NATL ACAD SCI USA 2006;103:18255-18260

- 30 Boon RA, Iekushi K, Lechner S, Seeger T, Fischer A, Heydt S, Kaluza D, Treguer K, Carmona G, Bonauer A, Horrevoets AJ, Didier N, Girmatsion Z, Biliczki P, Ehrlich JR, Katus HA, Muller OJ, Potente M, Zeiher AM, Hermeking H, Dimmeler S: Microrna-34a regulates cardiac ageing and function. Nature 2013;495:107-110.

31 Dorn GW, 2nd: Mir-34a and the cardiomyopathy of senescence: Salt pnuts, salt pnuts! Cell Metab 2013;17:629-630

-32 Tabuchi T, Satoh M, Itoh T, Nakamura M: Microrna-34a regulates the longevity-associated protein sirt1 in coronary artery disease: Effect of statins on sirt1 and microrna-34a expression. Clin Sci 2012;123:161-171

-33 Ito T, Yagi S, Yamakuchi M: Microrna-34a regulation of endothelial senescence. Biochem Bioph Res Co 2010;398:735-740

-34 Landsverk HB, Mora-Bermudez F, Landsverk OJ, Hasvold G, Naderi S, Bakke O, Ellenberg J, Collas P, Syljuasen RG, Kuntziger T: The protein phosphatase 1 regulator pnuts is a new component of the DNA damage response. EMBO Rep 2010; 11: 868-875.

-35 Kim H, Lee OH, Xin H, Chen LY, Qin J, Chae HK, Lin SY, Safari A, Liu D, Songyang Z: Trf2 functions as a protein hub and regulates telomere maintenance by recognizing specific peptide motifs. Nat Struct Mol Biol 2009;16:372-379.

-36 Loffredo FS, Pancoast JR, Lee RT: Keep pnuts in your heart. Circ Res 2013;113:97-99

37 Burgess ML, McCrea JC, Hedrick HL: Age-associated changes in cardiac matrix and integrins. Mech Ageing Dev 2001;122:1739-1756.

- 38 Swinnen M, Vanhoutte D, Van Almen GC, Hamdani N, Schellings MW, D'Hooge J, Van der Velden J, Weaver MS, Sage EH, Bornstein P, Verheyen FK, VandenDriessche T, Chuah MK, Westermann D, Paulus WJ, Van de Werf F, Schroen B, Carmeliet P, Pinto YM, Heymans S: Absence of thrombospondin-2 causes age-related dilated cardiomyopathy. Circulation 2009;120:1585-1597.

39 Wang M, Zhang J, Walker SJ, Dworakowski R, Lakatta EG, Shah AM: Involvement of nadph oxidase in ageassociated cardiac remodeling. J Mol Cell Cardiol 2010;48:765-772.

-40 Chen J, Huang ZP, Seok HY, Ding J, Kataoka M, Zhang Z, Hu X, Wang G, Lin Z, Wang S, Pu WT, Liao R, Wang DZ: Mir-17-92 cluster is required for and sufficient to induce cardiomyocyte proliferation in postnatal and adult hearts. Cir Res 2013; 112: 1557-1566. 


\section{Cellular Physiology Cell Physiol Biochem 2015;36:1679-1687 \begin{tabular}{l|l|l} 
DOI: 10.1159/000430141 & $\begin{array}{l}\text { O 2015 S. Karger AG, Basel } \\
\text { www.karger.com/cpb }\end{array}$
\end{tabular} \\ Wang et al.: Non-Coding RNAs Contributes to Cardiac Aging}

-41 Dews M, Homayouni A, Yu D, Murphy D, Sevignani C, Wentzel E, Furth EE, Lee WM, Enders GH, Mendell JT, Thomas-Tikhonenko A: Augmentation of tumor angiogenesis by a myc-activated microrna cluster. Nat Genet 2006;38:1060-1065.

42 Hebbar N, Wang C, Rangnekar VM: Mechanisms of apoptosis by the tumor suppressor par-4. J Cell Physiol 2012;227:3715-3721.

43 Zhao Y, Rangnekar VM: Apoptosis and tumor resistance conferred by par-4. Cancer Biol Ther 2008;7:18671874.

-44 Jazbutyte V, Fiedler J, Kneitz S, Galuppo P, Just A, Holzmann A, Bauersachs J, Thum T: Microrna-22 increases senescence and activates cardiac fibroblasts in the aging heart. Age 2013;35:747-762.

45 Kung JT, Colognori D, Lee JT: Long noncoding rnas: Past, present, and future. Genetics 2013;193:651-669.

46 Lee JT: Epigenetic regulation by long noncoding rnas. Science 2012; 338: 1435-1439.

47 Bergmann JH, Spector DL: Long non-coding rnas: Modulators of nuclear structure and function. Curr Opin Cell Biol 2014;26:10-18.

48 Gong C, Maquat LE: Lncrnas transactivate stau1-mediated mrna decay by duplexing with 3' utrs via alu elements. Nature 2011;470:284-288.

-49 Yoon JH, Abdelmohsen K, Srikantan S, Yang X, Martindale JL, De S, Huarte M, Zhan M, Becker KG, Gorospe M: Lincrna-p21 suppresses target mrna translation. Mol Cell 2012;47:648-655.

50 Anko ML, Neugebauer KM: Long noncoding rnas add another layer to pre-mrna splicing regulation. Mol Cell 2010;39:833-834.

-51 Cesana M, Cacchiarelli D, Legnini I, Santini T, Sthandier O, Chinappi M, Tramontano A, Bozzoni I: A long noncoding rna controls muscle differentiation by functioning as a competing endogenous rna. Cell 2011;147:358-369.

-52 Schmitt AM, Chang HY: Gene regulation: Long rnas wire up cancer growth. Nature 2013;500:536-537.

53 Vausort M, Wagner DR, Devaux Y: Long noncoding rnas in patients with acute myocardial infarction. Cir Res 2014;115:668-677.

54 Liu H, Song G, Zhou L, Hu X, Liu M, Nie J, Lu S, Wu X, Cao Y, Tao L, Chen L, Qian L: Compared analysis of lncrna expression profiling in pdk1 gene knockout mice at two time points. Cell Physiol Biochem 2013;32:1497-1508

55 Barry G: Integrating the roles of long and small non-coding rna in brain function and disease. Mol Psychiatry 2014;19:410-416.

-56 Abdelmohsen K, Panda A, Kang MJ, Xu J, Selimyan R, Yoon JH, Martindale JL, De S, Wood WH, 3rd, Becker KG, Gorospe M: Senescence-associated lncrnas: Senescence-associated long noncoding rnas. Aging Cell 2013;12:890-900.

57 Tripathi V, Shen Z, Chakraborty A, Giri S, Freier SM, Wu X, Zhang Y, Gorospe M, Prasanth SG, Lal A, Prasanth $\mathrm{KV}$ : Long noncoding rna malat1 controls cell cycle progression by regulating the expression of oncogenic transcription factor b-myb. PLoS Genet 2013;9:e1003368. 